\title{
Rat white adipocytes activate p85/p110 PI3K and induce PM GLUT4 in response to adrenoceptor agonists or aluminum fluoride
}

\author{
Y Ohsaka ${ }^{1,3}$, Y Nomura ${ }^{2,3}$ \\ ${ }^{1}$ Department of Pharmacology, Faculty of Pharmaceutical Sciences, Chiba Institute of Science, \\ Choshi, Japan \\ ${ }^{2}$ Yokohama College of Pharmacy, Yokohama, Japan \\ ${ }^{3}$ Department of Pharmacology, Faculty of Pharmaceutical Sciences, Hokkaido University, \\ Sapporo, Japan
}

Received: March 18, 2014

Accepted: December 3, 2015

\begin{abstract}
Adipocyte responses to adrenergic and $\beta$-adrenoceptor(-AR) (adrenoceptor) regulation are not sufficiently understood, and information helpful for elucidating the adrenoceptor-responsive machinery is insufficient. Here we show by using immunoprecipitated kinase analysis with a phosphatidylinositol 3-kinase (PI3K) p85 antibody that PI3K activation was induced by treatment with 10 or $100 \mu \mathrm{M}$ norepinephrine (NE) for 15 min or with $10 \mathrm{mM}$ aluminum fluoride (AF, a guanosine triphosphate (GTP)-binding $(\mathrm{G})$ protein activator) for 20 min in white adipocytes (rat epididymal adipocytes) and that treatment with pertussis toxin (PTX, a G-protein inactivator) inhibited PI3K activation induced by the 20 -min treatment with AF in the cells. In addition, western blot analysis revealed that glucose transporter 4 (GLUT4) level in the adipocyte plasma membrane (PM) fraction was increased by treatment with $10 \mu \mathrm{M} \mathrm{NE}, 100 \mu \mathrm{M}$ dobutamine (DOB, a $\beta_{1}$-AR agonist), or $0.1 \mu \mathrm{M}$ CL316243 (CL, a $\beta_{3}$-AR agonist) for $30 \mathrm{~min}$ or with $10 \mathrm{mM} \mathrm{AF}$ for $20 \mathrm{~min}$. NE or AF treatment triggered 2-deoxyglucose (2-DG) uptake into adipocytes under the above conditions. Our results advance the understanding of responses to adrenoceptor regulation in white adipocytes and provide possible clues for clarifying the machinery involved in adrenergic and $\beta$-AR responses in the cells.
\end{abstract}

Keywords: aluminum fluoride, CL316243, dobutamine, glucose transport, glucose transporter 4, norepinephrine, p85/p110, phosphatidylinositol 3-kinase, plasma membrane, white adipocytes

Adrenergic agonists induce various responses, including phosphorylation, expression, and transport responses, in adipocytes. Alterations in adrenoceptors such as $\beta$-ARs are implicated in the development of adipocyte disorders $(2,24)$, and signaling molecules associated with the adrenoceptors can be targeted to improve adipocyte dysregulation. However, responses to adrenoceptor regulation in adipocytes and the adrenoceptor-responsive machinery in the cells have not been fully elucidated.

Glucose is incorporated into rat epididymal adipocytes treated with epinephrine (EPI, 0.1-10 $\mu \mathrm{M}$ ) for $15 \mathrm{~min}$ in a non-selective $\beta$-AR antagonist-sensitive manner (22). When compared to EPI, NE has a higher binding affinity for $\beta$-AR (21) and a lower $50 \%$ effective concentration (26) in white adipocytes (adipocytes). The response to stress included an

Corresponding author: Yasuhito Ohsaka

Department of Pharmacology, Faculty of Pharmaceutical Sciences, Chiba Institute of Science

15-8 Shiomi-cho, Choshi, Chiba 288-0025, Japan

E-mails: y-ohsaka@live.jp; y-ohsaka@cis.ac.jp 
increase in the plasma level of NE in rats (20). However, it remains unclear whether glucose transport is increased following NE treatment at $\geq 0.1 \mu \mathrm{M}$ in adipocytes, although the effect of NE at low concentrations on glucose transport has been examined (8). The regulatory machinery involved in glucose transport responses to adrenergic agonists in the cells is not well understood.

In adipocytes, which mainly express $\beta_{1}$ - and $\beta_{3}$-ARs (26), treatment with adrenergic and non-selective or selective $\beta$-AR agonists for $\leq 15$ min modulates G-protein signaling to adenylyl cyclase (AC)-related responses $(4,33,40)$. An AC-related response to adrenergic agonists including $\mathrm{NE}$ or to a non-selective $\beta$-AR agonist is inhibited in adipocytes treated with a $\beta_{1}$-AR antagonist or non-selective $\beta$-AR antagonist (for $\beta_{1}$ - and $\beta_{3}$-ARs) $(11,19,26$, 34). The inhibitor wortmannin inactivates several molecules including p85/p110 PI3K (p85/ p110) (14) and inhibits a 10-min non-selective or selective $\beta$-AR response in adipocytes $(6,41)$. The p $85 / \mathrm{p} 110$ activity was increased by not only a phosphotyrosine peptide but also $\mathrm{G}$ protein in vitro (14), and expression of the p110 catalytic subunit of PI3K in adipocytes increased GLUT4 (an insulin-regulatable glucose transporter) expression in the PM (38). In adipocytes treated for 10 min with NE $(10 \mu \mathrm{M})$, PI3K activation in immunoprecipitation with a phosphotyrosine antibody has been examined (17). However, it remains unclear whether NE activates PI3K in immunoprecipitation with the PI3K p85 regulatory subunit antibody, and the effect of NE on glucose transporter expression in the adipocyte PM is unknown.

Glucose uptake into adipocytes is increased following treatment for $30 \mathrm{~min}$ with the selective $\beta$-AR agonist DOB $(100 \mu \mathrm{M})$ or CL $(0.1 \mu \mathrm{M})(26)$ as well as adrenergic and nonselective $\beta$-AR agonists $(0.1-100 \mu \mathrm{M})(32)$. Adrenergic agonists or non-selective or selective $\beta$-AR agonists alter AC activity in adipocytes. Aluminum fluoride acts as an analogue of the $\gamma$-phosphate of GTP in nucleotides (3) and modulates the AC system, and glucose transport is induced by treatment for $10 \mathrm{~min}$ with a fluoride ion $(3-10 \mathrm{mM}$, the stimulatory effects of which were blocked by a chelator of the aluminum ion) (37), which is a G-protein activator. Previous studies showed that PM GLUT4 expression and glucose transport in adipocytes were induced by treatment for $\leq 30 \mathrm{~min}$ with a non-hydrolyzable GTP analogue (36) or adenosine 3',5'-cyclic monophosphate (cAMP) analogue (16). It is unclear whether DOB, $\mathrm{CL}$, or AF induces PM GLUT4 in adipocytes. The $\beta$-AR-mediated machinery or the type of glucose transporter involved in the induction of glucose transport by the selective $\beta$-AR agonist, adrenergic and non-selective $\beta$-AR agonists, or AF is not well understood. Information helpful for elucidating the regulatory machinery involved in adrenoceptor responses is insufficient.

Treatment with a non-hydrolyzable GTP analogue for 15 min activated PI3K in adipocytes (36). However, it remains unclear whether trimeric G-protein signaling regulates $\mathrm{PI} 3 \mathrm{~K}$ activation in the cells and what type of PI3K is activated by this signaling. Furthermore, the signaling machinery involved in the GTP analogue-induced glucose transport-related responses, the AF-regulated responses, and also the GTP-dependent adrenoceptor responses is not sufficiently understood. PTX modulated trimeric G-protein signaling to AC in adipocytes (4). The effect of AF on the PI3K pathway in the cells is unknown, and it is unclear whether AF activates p85/p110 in adipocytes in a PTX-sensitive manner.

To investigate responses to adrenoceptor regulation in adipocytes and to obtain information helpful for elucidating the adrenoceptor-responsive machinery in the cells, we treated rat epididymal white adipocytes with $0.1-100 \mu \mathrm{M}$ NE for 15 min or with 5 or $10 \mathrm{mM}$ AF for 20 min and examined PI3K activation by immunoprecipitation using a PI3K p85 antibody, 
and the effect of PTX on the 20-min AF-induced PI3K activation was determined. Furthermore, we examined the GLUT4 level in the adipocyte PM fraction following treatment with $10 \mu \mathrm{M}$ NE, $100 \mu \mathrm{M}$ DOB, $0.1 \mu \mathrm{M}$ CL, or 5 or $10 \mathrm{mM} \mathrm{AF}$ for 20 or $30 \mathrm{~min}$ and determined glucose transport responses to NE or AF under the above conditions.

\section{Materials and Methods}

\section{Materials}

Aluminum chloride, ammonium hydroxide, chloroform, methanol, polyacrylamide, sodium fluoride, and sucrose were from Wako Chemicals (Osaka, Japan). Aprotinin, CGP20712A ${ }^{1}$ (a $\beta_{1}$-AR antagonist), $\mathrm{CL}^{2}$, DOB, propranolol (a non-selective $\beta$-AR antagonist), and PTX were kind gifts from Dr. Y. Tokumitsu (Hokkaido University, Japan). $\left[\gamma-{ }^{32} \mathrm{P}\right]$ adenosine triphosphate (ATP) and 2-deoxy-D-1,2-[ $\left.{ }^{3} \mathrm{H}\right]$ glucose $\left(\left[{ }^{3} \mathrm{H}\right] 2-\mathrm{DG}\right)$ were from Dupont NEN (Boston, MA). Ethylenediaminetetra acetic acid (EDTA) and 2-[4-(2-hydroxyethyl)-1piperazinyl] ethanesulfonic acid (HEPES) were from Dojindo Molecular Technologies (Kumamoto, Japan). Other chemicals (unless otherwise stated) were from Sigma-Aldrich Co. (St. Louis, MO).

\section{Preparation and treatment of adipocytes}

Epididymal adipose tissues were isolated from male animals (3-5 rats for each set of experiments, weighing between 200 and $300 \mathrm{~g}$ ) belonging to a Wistar-derived strain (Charles River Breeding Laboratories, Inc.) after they had been sacrificed by decapitation. Animal experiments, which were approved by the graduate school of pharmaceutical sciences, were conducted in accordance with the guidelines for animal experiments established by the Japanese Association for Laboratory Animal Science (15). The adipose tissues were digested in Krebs-Ringer bicarbonate (KRB) buffer containing 3\% bovine serum albumin (BSA, fatty-acid free) and $250 \mathrm{U} / \mathrm{ml}$ collagenase (type I, Worthington Biochemical Co., Freehold, NJ) as described previously (26) to yield adipocytes, which were suspended in the KRB buffer containing 3\% BSA at a final concentration of $10^{6}$ cells $/ \mathrm{ml}$ and incubated with or without $\mathrm{NE}, \mathrm{DOB}, \mathrm{CL}$, or $\mathrm{AF}$ at $37^{\circ} \mathrm{C}$ or pre-treated with PTX before the AF treatment. Additionally, the suspended adipocytes were incubated with insulin (15-30 min, 70 or 700 $\mathrm{nM}$ ), and adipocyte function was confirmed by examining PI3K activation, PM GLUT4 expression, and glucose transport. Furthermore, adrenergic and $\beta$-AR signaling was confirmed by examining the AC system (activation) in the membrane fraction of adipocytes treated with $\mathrm{NE}, \mathrm{DOB}$, or CL (for $10 \mathrm{~min}$ ) and also by examining AC activation (cAMP accumulation) in adipocytes treated with the following agents (for $10 \mathrm{~min}$ ): NE in the presence or absence of propranolol $(1-100 \mu \mathrm{M})$, DOB in the presence or absence of CGP20712A $(100 \mu \mathrm{M})$, or CL in the presence or absence of CGP $12177^{3}$ (a $\beta_{3}$-AR agonist, $\left.1 \mu \mathrm{M}\right)$ or propranolol $(5 \mu \mathrm{M})$. Membrane AC activation and cellular cAMP accumulation were determined as described previously (26).

\footnotetext{
${ }^{1}( \pm)$-[2-(3-carbamoyl-4-hydroxyphenoxy)-ethylamino]-3-[4-(1-methyl-4-trifluoromethyl-2-imidazolyl)-phenoxy]-2propanolmethane sulphonate

2 disodium $(R, R)-5$-[2-[[2-(3-chlorophenyl)-2-hydroxyethyl]-amino]propyl]-1,3-benzodioxole-2,2-dicarboxylate

3 4-[3-t-butylamino-2-hydroxypropoxy]benzimidazol-2-one
} 
Measurement of PI3K activation

Adipocytes were separated from the medium and lysed as described previously (27). Aliquots of cell lysates were mixed with anti-PI3K (p85) rabbit antibody (Upstate Biotechnology Inc., Lake Placid, NY) that had been preadsorbed on protein G-Sepharose (GE Healthcare Life Sciences, Piscataway, NJ) and then stirred overnight at $4^{\circ} \mathrm{C}$. Following centrifugation, immune complexes recovered in the pellet were washed and then incubated in a buffer containing phosphatidylinositol (PI) (Serdary Research Laboratories, Ontario, Canada) and $\left[\gamma-{ }^{32} \mathrm{P}\right]$ ATP, as described previously (12). Reaction mixtures containing radiolabeled PI were separated by thin-layer chromatography on a Silica Gel 60 plate (Merck Millipore, Darmstadt, Germany) in a chloroform/methanol/25\% ammonium hydroxide/water (100: $70: 25: 15$, v/v) mixture. ${ }^{32} \mathrm{P}$-labeled PI was detected and quantified by using a Fuji BAS2000 Bioimaging Analyzer (Fuji Photo Film Co., Tokyo, Japan).

\section{Preparation of PM fractions}

Adipocytes were homogenized by using a Dounce homogenizer in a buffer containing $10 \mu \mathrm{g} /$ $\mathrm{ml}$ aprotinin, $1 \mathrm{mM}$ EDTA, $20 \mathrm{mM}$ HEPES (pH 7.4), $5 \mu \mathrm{g} / \mathrm{ml}$ leupeptin, $1 \mathrm{mM}$ phenylmethylsulfonyl fluoride, and $0.25 \mathrm{mM}$ sucrose. PM fractions were prepared as described previously (27).

\section{Western blot analysis}

PM fractions prepared from aliquots of adipocyte homogenates were separated by $10 \%$ sodium dodecyl sulfate-polyacrylamide gel electrophoresis and then transferred onto a Hybond-enhanced chemiluminescence (ECL) filter (GE Healthcare Life Sciences). The separated proteins transferred onto the filter were incubated for $1 \mathrm{~h}$ with anti-GLUT4 rabbit antibody (1:1000, carboxy-terminal polypeptide [27]). After incubating with a horseradish peroxidase-conjugated anti-rabbit immunoglobulin-G antibody (1:2500; GE Healthcare Life Sciences), the immune complexes were detected on X-ray film (Kodak X-Omat AR; EastmanKodak Co., Rochester, NY) by using an ECL detection system (GE Healthcare Life Sciences). The blots on the film were quantified using the National Institutes of Health Image program (http://rsb.info.nih.gov/nih-image/).

\section{Measurement of glucose transport}

Adipocytes were incubated with agents in KRB buffer containing 3\% BSA (pH 7.4) in a 95\% oxygen and 5\% carbon dioxide atmosphere and further incubated for 3 min with $0.2 \mathrm{mM}$ $\left[{ }^{3} \mathrm{H}\right] 2-\mathrm{DG}$, and 2-DG uptake was determined as described previously (33).

\section{Statistical analysis}

The results were analyzed using analysis of variance with Scheffe's test, and differences between 2 groups were evaluated by using unpaired Student's $t$-test. Statistical significance was defined as $P<0.05$ and is indicated with an asterisk mark $(*)$. Values are presented as means \pm standard deviation of 3 or 4 experiments.

\section{Results}

\section{Induced PI3K activation in NE-treated adipocytes}

Treatment with 10 or $100 \mu \mathrm{M}$ NE activated PI3K (Fig. 1a); the increase in PI3K activation was not significant following treatment with $1 \mu \mathrm{M} \mathrm{NE}$ (and also $0.1 \mu \mathrm{M}$, data not shown). Insulin activated PI3K (Fig. 1b). PI3K activation did not vary in the groups of adipocytes 
incubated in the absence of agonists (Fig. 1a inset, data for the group without insulin not shown). Adipocytes treated with 10 or $100 \mu \mathrm{M}$ NE induced cAMP accumulation in a propranolol-sensitive manner (Fig. 1c, data for $100 \mu \mathrm{M}$ NE not shown) and activated $\beta$-ARdependent signaling.

a

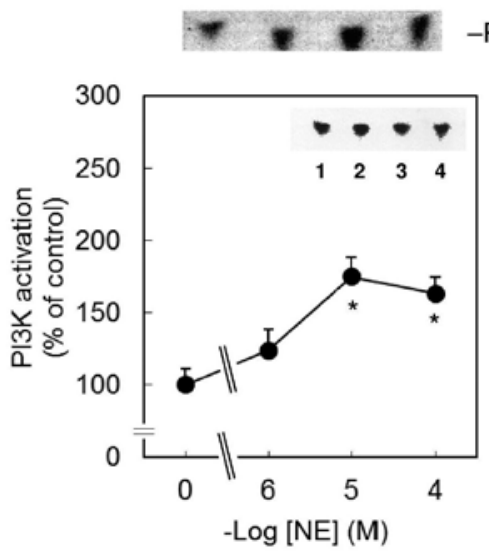

b

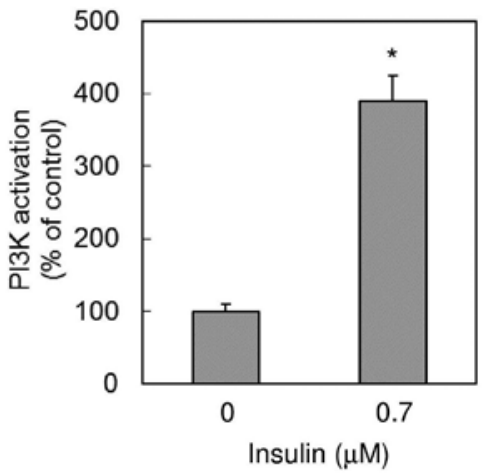

C

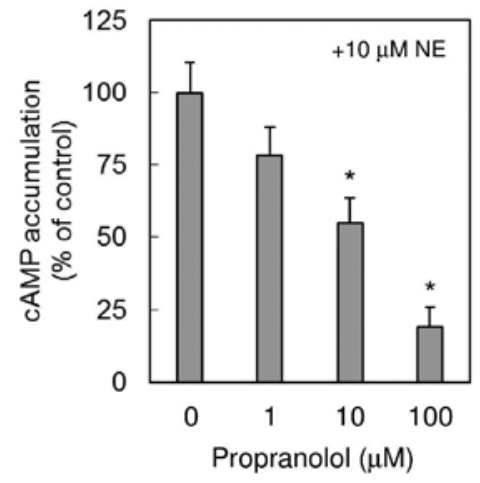

Fig. 1. Effects of NE on PI3K activation in adipocytes.

Legend: Adipocytes suspended in KRB buffer containing 3\% BSA were treated for 15 min with the indicated concentrations of NE (a) or insulin (b).

The adipocytes were also treated for $10 \mathrm{~min}$ with $10 \mu \mathrm{M} \mathrm{NE}$ in the presence of the indicated concentrations of propranolol (c). PI3K activation was determined by immunoprecipitation with a PI3K p85 subunit antibody and by measuring ${ }^{32} \mathrm{P}$ incorporation in PI ( $\mathrm{a}$ and $\mathrm{b}$ ),

and cAMP (adenosine 3',5'-cyclic monophosphate) accumulation was determined by examining the amount of cAMP produced in adipocytes (c). Insets show PI3K activation in adipocytes treated for $15 \mathrm{~min}$ in the absence of NE (a, 1-4). Autoradiographic images (a and insets) represent typical results (3 or 4 experiments).

$* P<0.05$ vs. cells not treated with NE (a) or insulin (b) or cells treated with NE in the absence of propranolol (c).

Here and in Figs 2 and 3, NE, PI3K and PI 3-P indicate norepinephrine, phosphatidylinositol 3-kinase, and phosphatidylinositol 3-phosphate, respectively. 
Induced PTX-sensitive PI3K activation in AF-treated adipocytes

Following treatment with $10 \mathrm{mM}$ AF, PI3K was activated (Fig. 2a); this response was not induced significantly following $5 \mathrm{mM}$ AF treatment. PI3K activation caused by the $10 \mathrm{mM}$ AF treatment was not induced by PTX pre-treatment (Fig. 2b).

a

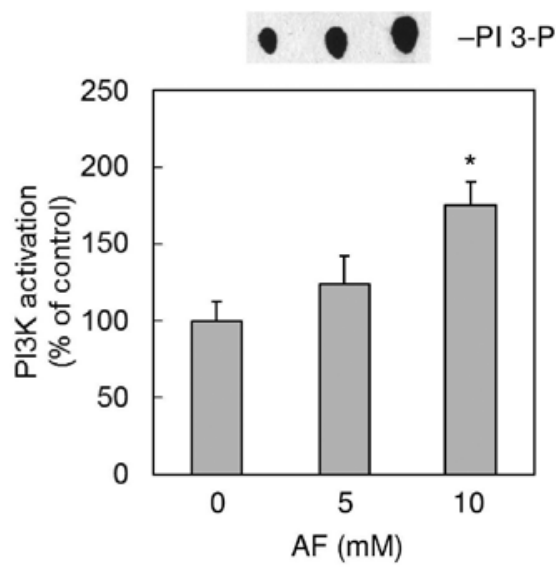

b

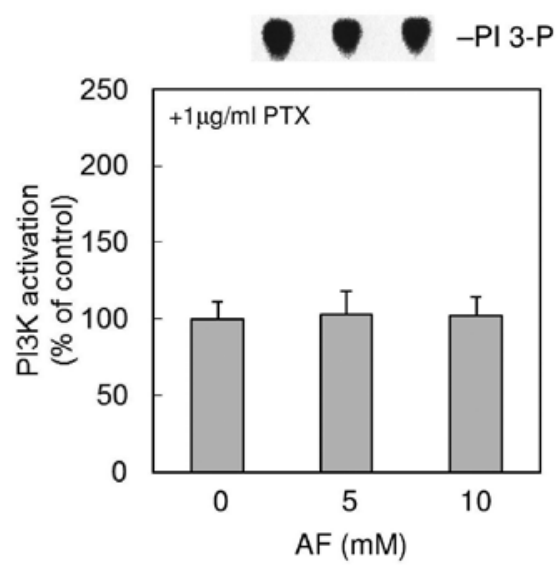

Fig. 2. Effects of AF on PI3K activation following treatment with or without PTX in adipocytes.

Legend: Adipocytes suspended in KRB buffer containing 3\% BSA were treated with the indicated concentrations of AF for $20 \mathrm{~min}$ ( $\mathrm{a}$ and $\mathrm{b}$ ). The adipocytes were also treated with $1 \mu \mathrm{g} / \mathrm{ml}$ PTX (pertussis toxin) for 60 min before the 20-min AF treatment (b). PI3K activation was determined by immunoprecipitation with a PI3K p85 subunit antibody and by measuring ${ }^{32} \mathrm{P}$ incorporation in PI ( $\mathrm{a}$ and $\mathrm{b}$ ).

Autoradiographic images ( $\mathrm{a}$ and $\mathrm{b}$ ) represent typical results ( 3 or 4 experiments).

$* P<0.05$ vs. cells not treated with AF (a). Here and in Fig. 5, AF indicates aluminum fluoride.

Increased PM GLUT4 expression and glucose transport in NE-treated adipocytes

Treatment with $10 \mu \mathrm{M}$ NE increased the GLUT4 level in the adipocyte PM fraction (Fig. 3a). No variation in the PM GLUT4 level was observed in adipocytes incubated in the absence of NE (Fig. 3a inset). Glucose uptake was increased by $10 \mu \mathrm{M}$ NE treatment (Fig. 3b); the increase in glucose uptake was not significant following treatment with $1 \mu \mathrm{M} \mathrm{NE}$ (and also $0.1 \mu \mathrm{M}$, data not shown) and was increased by $100 \mu \mathrm{M}$ NE. Insulin treatment increased the glucose uptake (Fig. 3c), and $\beta$-AR-responsive signaling to AC was activated by 10 or 100 $\mu \mathrm{M} N E$ in the adipocyte membrane (Fig. 3d).

\section{Induced PM GLUT4 in DOB- or CL-treated adipocytes}

PM GLUT4 level was increased following treatment with $100 \mu \mathrm{M}$ DOB or $0.1 \mu \mathrm{M}$ CL (Fig. $4 \mathrm{a}-\mathrm{c}$ ). Insulin increased the PM GLUT4 level (Fig. 4a and b), and $\beta$-AR-dependent signaling was activated by DOB or CL in the adipocyte membrane (Fig. 4d) and in adipocytes (data not shown). 
a

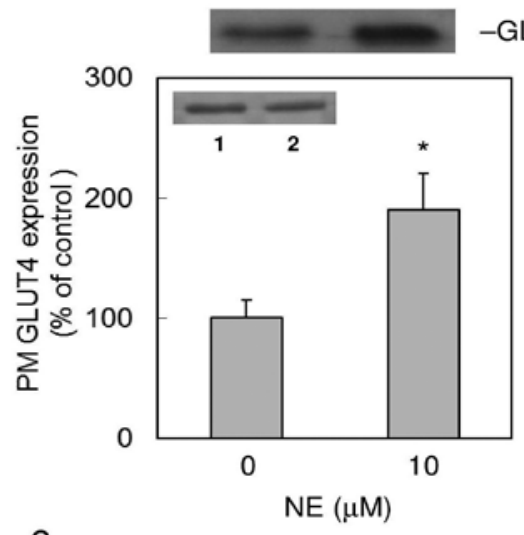

C

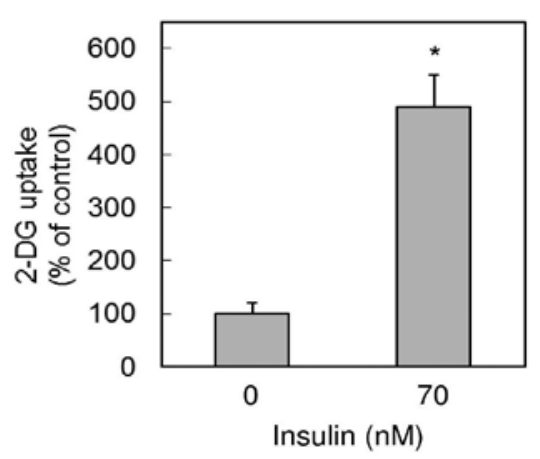

b
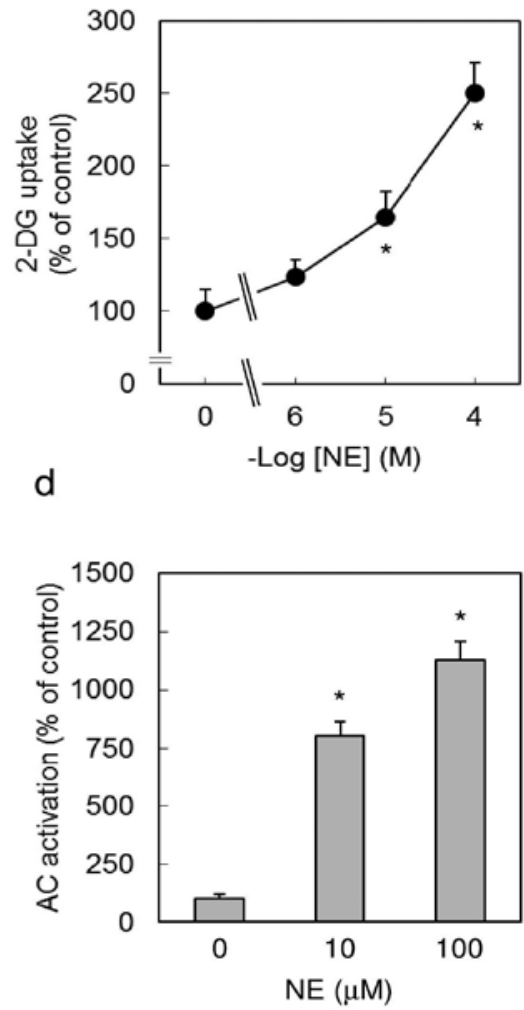

Fig. 3. Effects of NE on PM GLUT4 expression and glucose transport in adipocytes.

Legend: Adipocytes suspended in KRB buffer containing 3\% BSA were treated for 30 min with the indicated concentrations of NE ( $a$ and $b$ ) or insulin (c). The adipocytes were also treated for 10 min with the indicated concentrations of NE (d). GLUT4 level in PM fractions obtained from adipocytes was determined by western blotting using a GLUT4 antibody (a), and glucose transport was assessed by $\left[{ }^{3} \mathrm{H}\right] 2-\mathrm{DG}$ uptake into adipocytes ( $\mathrm{b}$ and $\mathrm{c}$ ). AC activation was determined by examining the amount of cAMP produced from ATP added to the adipocyte membrane fraction (d).

Insets show PM GLUT4 expression in adipocytes treated for $30 \mathrm{~min}$ without NE (a, 1 and 2).

Blotted lanes (a and insets) represent typical results ( 3 or 4 experiments). $* P<0.05$ vs. cells not treated with NE (a, b, and d) or insulin (c). Here and in Figs 4 and 5, PM, GLUT4, 2-DG and AC indicate plasma membrane, glucose transporter 4, 2-deoxyglucose, and adenylyl cyclase, respectively.

\section{Induced PM GLUT4 expression and glucose transport in AF-treated adipocytes}

Following $10 \mathrm{mM} \mathrm{AF}$ treatment, the PM GLUT4 level and glucose uptake were increased (Figs $5 \mathrm{a}$ and $5 \mathrm{~b}$ ); these responses were not observed significantly following $5 \mathrm{mM} \mathrm{AF}$ treatment. Insulin induced glucose transport-related responses (Fig. 5c, data for glucose uptake not shown). No variation in the PM GLUT4 level was observed in adipocytes incubated without agonists (data not shown). 
a

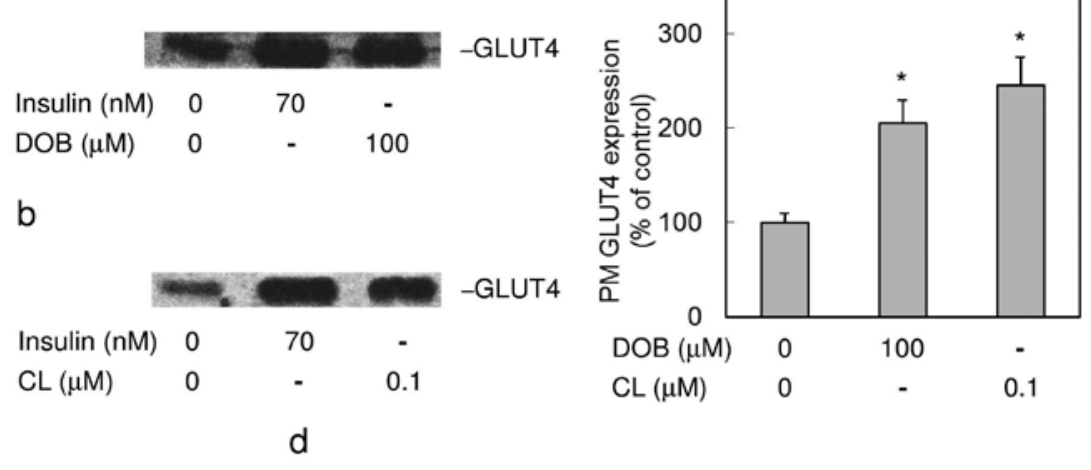

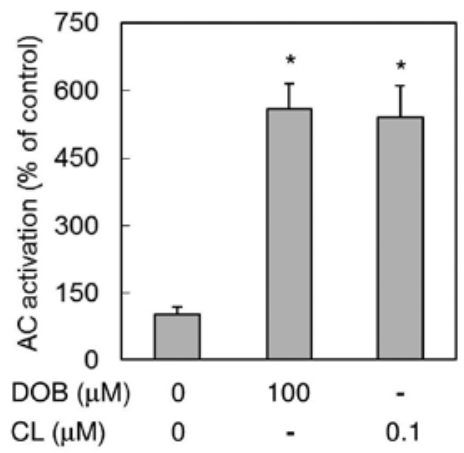

Fig. 4. Effects of DOB and CL on PM GLUT4 expression in adipocytes.

Legend: Adipocytes suspended in KRB buffer containing 3\% BSA were treated for 30 min with the indicated concentrations of DOB (dobutamine, $a$ and c), CL (CL316243, b and c), or insulin ( $a$ and b). The adipocytes were also treated for 10 min with the indicated concentrations of DOB or CL (d). GLUT4 level in PM fractions was determined by western blotting using a GLUT4 antibody $(\mathrm{a}-\mathrm{c})$, and AC activation was determined by examining the amount of cAMP produced from ATP added to the adipocyte membrane fraction (d). Blotted lanes (a and b) represent typical results ( 3 experiments). ${ }^{*} P<0.05$ vs. cells not treated with DOB (c and d) or CL (c and d).

\section{Discussion}

In this study, we found that NE or AF treatment activated p85/p110 PI3K, and AF-activated p85/p110 was inhibited by PTX. Previous studies mainly examined the brown adipocyte machinery involved in glucose transport responses to $\mathrm{NE}(5,28)$. In white adipocytes, NE, DOB, CL, or AF treatment induced PM GLUT4, and glucose transport was increased by NE and also AF treatment.

Experiments using PTX or $\left[{ }^{32} \mathrm{P}\right] \mathrm{GTP}$ showed that $\mathrm{G}$ protein or G-protein signaling to AC-related responses was modulated by $\beta_{1}$ - or $\beta_{3}$-AR stimulation in adipocytes $(4,35,40)$. In the membrane fraction, the $\beta_{1}$-AR agonist xamoterol, the $\beta_{3}$-AR agonist BRL37344, ${ }^{4}$, or propranolol binds to the high and/or low affinity binding sites of $\left[{ }^{3} \mathrm{H}\right] \mathrm{CGP} 12177$ (11); this

\footnotetext{
4 sodium [4-(2-[[2-(3-chlorophenyl)-2-hydroxyethyl]amino]propyl)phenoxy]acetate 
a

b
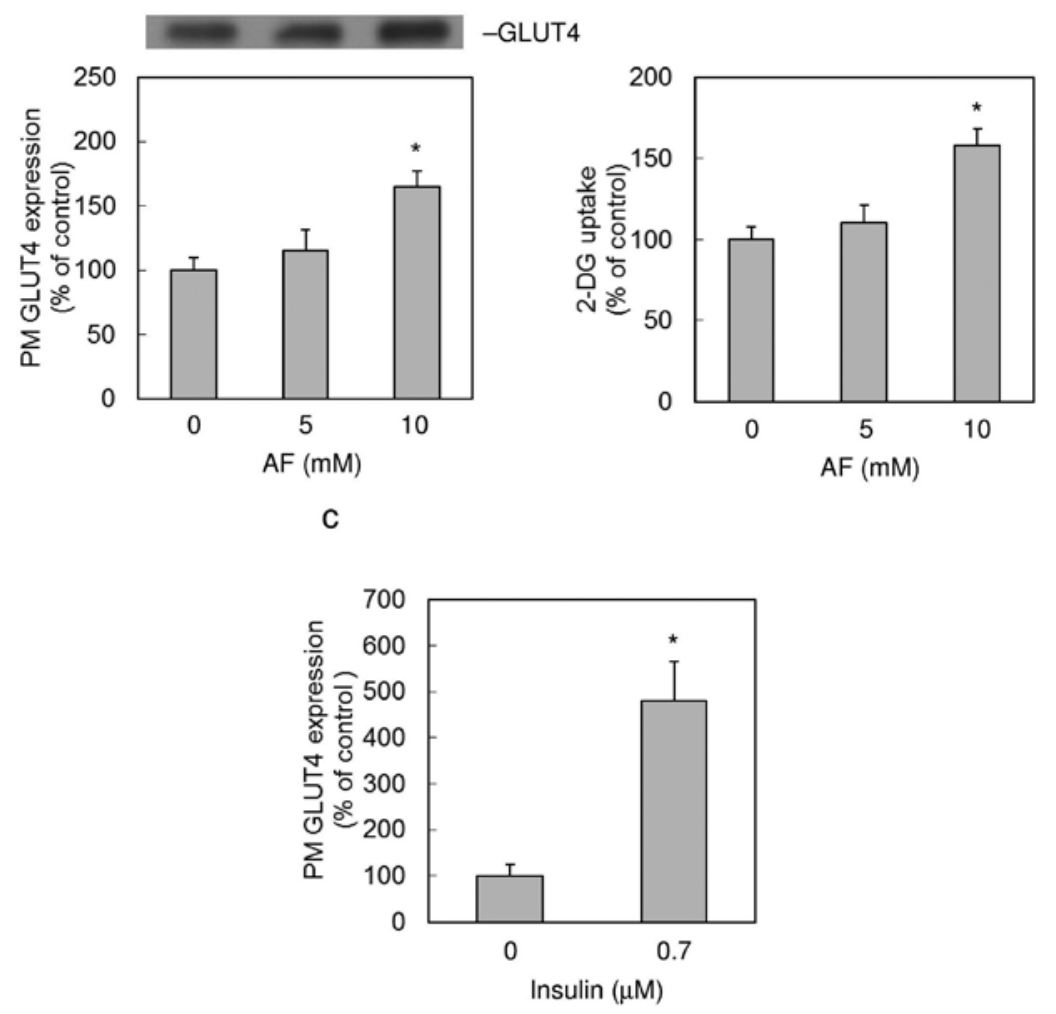

Fig. 5. Effects of AF on PM GLUT4 expression and glucose transport in adipocytes.

Legend: Adipocytes suspended in KRB buffer containing 3\% BSA were treated for 20 min with the indicated concentrations of AF ( $a$ and $b$ ) or insulin (c). GLUT4 level in PM fractions was determined by western blotting using a GLUT4 antibody (a and c). Glucose transport was assessed by [ $\left.{ }^{3} \mathrm{H}\right] 2-\mathrm{DG}$ uptake into adipocytes (b). Blotted lanes (a) represent typical results (4 experiments). $* P<0.05$ vs. cells not treated with AF ( $\mathrm{a}$ and $\mathrm{b}$ ) or insulin (c).

radioligand is a $\beta_{1}$ - or $\beta_{2}-\mathrm{AR}$ antagonist and a $\beta_{3}$-AR agonist. AC-related responses to xamoterol (or DOB), CGP12177 (or CL), and BRL37344 in adipocytes are inhibited by CGP20712A (11), the $\beta_{3}$-AR antagonist SR59230A A $^{5}$ (9), and propranolol (34), respectively. In preparatory experiments, CGP20712A and CGP12177 suppressed DOB- and CL-induced AC activation, respectively, and propranolol inhibited $\mathrm{AC}$ activation induced by NE (Fig. 1c) or CL (data not shown). PTX also modulates G-protein signaling to AC in response to adrenergic stimulation (33) or the non-selective $\beta$-AR agonist isoproterenol (ISO, $[11,26])$ $(4,33,40)$, and similarly to xamoterol $\left(\beta_{1}\right)$ and BRL37344 $\left(\beta_{3}\right)$, NE, EPI or ISO binds to the high and low affinity binding sites of $\left[{ }^{3} \mathrm{H}\right] \mathrm{CGP} 12177$ (11). Treatment with NE, DOB, or CL is thought to activate $\mathrm{G}$ protein and G-protein signaling to AC via $\beta$-AR.

\footnotetext{
5 3-(2-ethylphenoxy)-1-[(1S)-1,2,3,4-tetrahydronaphth-1-ylaminol]-(2S)-2-propanol oxalate
} 
Adipocytes express $\mathrm{G}$ proteins including $\mathrm{G}_{\mathrm{s}}(35)$ and $\mathrm{p} 85 / \mathrm{p} 110_{\alpha / \beta}$ isoforms (29). These isoforms of PI3K are activated by a phosphotyrosyl peptide that contains a motif that interacts with the $\mathrm{p} 85$ subunit or by the $\mathrm{G}$-protein $\mathrm{G}_{\beta \gamma}$ subunits or both in vitro (14). G-protein activation results in dissociation of the $\mathrm{G}_{\alpha}$ and $\mathrm{G}_{\beta \gamma}$ subunits of $\mathrm{G}$ protein and alters AC activity (25). A cAMP analogue activated tyrosine kinase of partially purified insulin receptors in vitro (7). NE or AF treatment may activate a p85/p110 isoform(s) through the $\mathrm{G}_{\beta \gamma}$ subunits that are dissociated from $\mathrm{G}$ protein and/or through the phosphotyrosyl peptide that interacts with the p85 subunit.

Adipocytes also express PTX-sensitive $G$ proteins such as $G_{i 1}$ and $G_{i 2}$ (35). PTX pretreatment remarkably enhances the cAMP level increased by adrenoceptor regulation in adipocytes $(4,33,40)$, and p85/p110 activated in insulin-treated adipocytes was inhibited by exposure to a high concentration of cAMP (27). PTX-induced inactivation of AF-activated PI3K may be due to inhibition of PTX-sensitive G-protein subunit signaling, including $\mathrm{G}_{\mathrm{i}}$ subunit signaling to AC, and induction of markedly accumulated cAMP signaling. AF treatment seems to activate PI3K by signaling through $G$ proteins such as $G_{S}$ and PTXsensitive $\mathrm{G}$ proteins and/or its signaling to $\mathrm{AC}$.

3-Phosphoinositides can be produced upon PI3K activation in a p85-containing immunocomplex (18). Treatment of adipocytes with 3-phosphoinositides or expression of a 3 -phosphoinositide-dependent kinase in adipocytes activates some kinases (13, 31), including protein kinase $\mathrm{B}$ (PKB). NE- or AF-activated PI3K may induce an alteration in the cellular levels of inositol phospholipids and activate a 3-phosphoinositide-responsive kinase(s).

Glucose transport in adipocytes that were tissue-isolated from rats weighing $\geq 300 \mathrm{~g}$ was not increased following NE treatment at high concentrations $(\geq 0.1 \mu \mathrm{M})$ (8). Adipocytes tissue-isolated from rats weighing between 300 and $400 \mathrm{~g}$ (but not those from rats weighing $<300 \mathrm{~g}$ ) responded to the $\alpha_{2}$-AR agonist UK143046 (10); this agonist activates $\mathrm{G}_{\mathrm{i}}$ and suppresses a response to an enzyme that modulates the AC system. No induction of NE responses at high concentrations in $\geq 300 \mathrm{~g}$ rat adipocytes seems to result from modulation of the adrenoceptor signaling that responds to $\mathrm{NE}$ including the $\mathrm{G}_{\mathrm{i}}$-coupled $\alpha$-AR signaling that influences the AC system.

Similarly to results of previous studies showing responses to adrenoceptor agonists, such as EPI, ISO and selective $\beta$-AR agonists $(22,26,32)$, or a G-protein activator (36) or cAMP analogue (16), this study showed that NE, DOB, CL, and AF induced responses including increased glucose transport and PM GLUT4 expression and that PM GLUT4 was induced under the same conditions as those that increased glucose transport. Glucose transport seems to increase as a result of increased PM GLUT4 expression in response to NE, DOB, $\mathrm{CL}$, or AF. These agents are thought to induce glucose transport-related responses by signaling through $\mathrm{G}$ protein and $\mathrm{AC}$ activation.

Treatment of adipocytes with a cAMP analogue for 30 min increased GLUT4 expression in the PM while decreasing GLUT4 level in the microsomal fraction (16). In addition, NE treatment for $30 \mathrm{~min}$ transiently altered the total cellular GLUT4 expression (5). Induction of PM GLUT4 by NE, DOB, CL, or AF may result from GLUT4 translocation from an intracellular region to the adipocyte PM and/or from increased total GLUT4 expression. $\left[{ }^{14} \mathrm{C}\right]$ glucose is metabolized into carbon dioxide, for example, in adipocytes treated with agonists that modulate AC (30). Following NE, DOB, CL, or AF treatment, glucose metabolism may be activated after glucose has been incorporated into adipocytes.

\footnotetext{
6 5-bromo-6-(2-imidazolin-2-ylamino)quinoxaline 
NE treatment induces AC-related responses (26, Fig. 3d). Such responses are also induced by DOB or CL $(11,26$, Fig. $4 d)$. The regulatory machinery that responds to NE appears to be similar to the regulatory machinery that responds to DOB or CL. AC-related responses were also observed following EPI or ISO treatment $(4,26,32,33,40)$, and ISO treatment induced glucose transport together with increased glucose transporter expression in the adipocyte PM (32). The ability to induce PM GLUT4 through DOB or CL treatment may be useful for examining the $\beta$-AR-mediated machinery or the type of glucose transporter involved in the induction of glucose transport by selective $\beta$-AR agonists or EPI and in the induction of glucose transport-related responses by ISO or NE.

Adipocytes express $\mathrm{G}$ proteins including $\mathrm{G}_{\mathrm{S}}$ and $\mathrm{G}_{\mathrm{i}}$ subtypes $\mathrm{G}_{\mathrm{i1}-3}(35)$. These $\mathrm{G}$ proteins seem to regulate the AF-induced PM GLUT4 expression and glucose transport in the cells. AF induced glucose transport-related responses similar to those induced by NE (Fig. 3a and b), DOB (26, Fig. 4a and c), or CL (26, Fig. 4b and c) and with ISO (32) or EPI (22, 32). The ability to induce PM GLUT4 expression or glucose transport through AF treatment may be useful for examining the regulatory machinery involved in the induction of glucose transport-related responses by NE, DOB, CL, or ISO and in the induction of glucose transport by EPI or AF.

The expression of a 3-phosphoinositide-responsive kinase or PKB in adipocytes induces PM GLUT4 $(13,39)$. CL treatment for 10 min activated PKB in adipocytes in a wortmanninsensitive manner and also a cAMP-dependent kinase (PKA) inhibitor-sensitive manner (41). Likewise, ISO treatment $(3 \mu \mathrm{M})$ for 10 min activated $\mathrm{p} 70^{\mathrm{S} 6 \mathrm{~K}} 7$ in adipocytes in a wortmanninsensitive manner (6), while wortmannin did not significantly inhibit PKB activated by $1 \mu \mathrm{M}$ ISO treatment for $10 \mathrm{~min}$ (23). An AC-related response to $1 \mu \mathrm{M}$ ISO was inhibited (partially inhibited) by CGP20712A (11). $\beta_{1}$-AR signaling may activate PKB through wortmannininsensitive signaling, and wortmannin-insensitive PKB signaling may mediate the increase in PM GLUT4 expression and glucose transport induced by DOB. In contrast, CL may induce glucose transport-related responses by activating PKB through wortmannin-sensitive or PKA-sensitive signaling. In this study, PI3K activation occurred before or concurrently with the induction of PM GLUT4 expression and glucose transport by NE or AF. NE, DOB, CL, or AF treatment may regulate glucose transport-related responses through a PI3K-dependent and/or -independent pathway, including the PKB pathway. Activated PI3K may be helpful for examining the signaling machinery involved in the induction of GLUT4 expression and glucose transport by NE or AF.

The GTP phosphate analogue AF induced PTX-sensitive PI3K activation in immunoprecipitation with a p85 antibody (Fig. 2b). Adipocytes seem to activate a p85/p110 isoform(s) in response to GTP-regulated signaling induced in the cells, and p85/p110 in adipocytes is regulated by PTX-sensitive trimeric G-proteins. AF-induced effects on p85/p110 activation that is sensitive to PTX may be helpful for examining the signaling machinery involved in the induction of PI3K activation, PM GLUT4 expression, and glucose transport by GTP analogue treatment and in the induction of glucose transport-related responses by AF treatment. AF induced PI3K activation similar to that induced by NE (Figs. 1a and 2a), and PTX pretreatment altered GTP-dependent signaling induced by adrenoceptor regulation $(4,33,40)$ as well as by AF treatment (Fig. 2b). The AF-induced effects on PI3K activation may also be helpful for examining the signaling machinery involved in the induction of PI3K activation

\footnotetext{
7 40S ribosomal protein S6 kinase
} 
and glucose transport-related responses by NE, in the induction of glucose transport-related responses by CL, and in the wortmannin-sensitive responses to ISO or CL.

3-Phosphoinositides can be produced upon insulin-induced PI3K activation in adipocytes (18). The expression of GLUT4 in the cells, which increases its cell surface expression, reduces the ability of insulin to induce PM GLUT4 translocation (1). Similarly to previous reports $(8,22,26,32,33)$, insulin responses were mimicked by NE, DOB, CL or AF in the present study. These agents may alter the ability of insulin to induce 3-phosphoinositidedependent responses and PM GLUT4 translocation. Examination of the adipocyte responses in the presence or absence of insulin may help to elucidate the role of the responses observed in this study.

Inhibitory experiments targeting molecules that respond to $\mathrm{DOB}, \mathrm{CL}, \mathrm{AF}$, or $\mathrm{NE}$ are needed to clarify the regulatory machinery involved in adrenergic and $\beta$-AR responses in adipocytes and also regulatory machinery present in the cells. Our results advance the understanding of responses to adrenoceptor regulation in white adipocytes and provide possible clues for clarifying the machinery involved in adrenergic and $\beta$-AR responses in the cells.

\section{Acknowledgements}

We thank Dr. O. Ezaki (National Institute of Nutrition, Japan) and Dr. Y. Tokumitsu for their advice on the antiGLUT4 antibody.

\section{REFERENCES}

1. Al-Hasani H, Yver DR, Cushman SW: Overexpression of the glucose transporter GLUT4 in adipose cells interferes with insulin-stimulated translocation. FEBS Lett. 460, 338-342 (1999)

2. Arner P, Hoffstedt J: Adrenoceptor genes in human obesity. J. Intern. Med. 245, 667-672 (1999)

3. Bigay J, Deterre P, Pfister C, Chabre M: Fluoroaluminates activate transducin-GDP by mimicking the $\gamma$-phosphate of GTP in its binding site. FEBS Lett. 191, 181-185 (1985)

4. Chaudhry A, MacKenzie RG, Georgic LM, Granneman JG: Differential interaction of $\beta_{1}$ - and $\beta_{3}$-adrenergic receptors with $\mathrm{G}_{\mathrm{i}}$ in rat adipocytes. Cell. Signal. 6, 457-465 (1994)

5. Dallner OS, Chernogubova E, Brolinson KA, Bengtsson T: $\beta_{3}$-Adrenergic receptors stimulate glucose uptake in brown adipocytes by two mechanisms independently of glucose transporter 4 translocation. Endocrinology 147 , 5730-5739 (2006)

6. Diggle TA, Moule SK, Avison MB, Flynn A, Foulstone EJ, Proud CG, Denton RM: Both rapamycin-sensitive and -insensitive pathways are involved in the phosphorylation of the initiation factor-4E-binding protein (4E$\mathrm{BP} 1$ ) in response to insulin in rat epididymal fat-cells. Biochem. J. 316, 447-453 (1996)

7. Eriksson JW, Lönnroth P, Smith U: Cyclic AMP impairs the rapid effect of insulin to enhance cell-surface insulin-binding capacity in rat adipocytes. Biochem. J. 288, 625-629 (1992)

8. Faintrenie G, Géloën A: Alpha-1 adrenergic stimulation of glucose uptake in rat white adipocytes. J. Pharmacol. Exp. Ther. 286, 607-610 (1998)

9. Galitzky J, Langin D, Verwaerde P, Montastruc J-L, Lafontan M, Berlan M: Lipolytic effects of conventional $\beta_{3}$-adrenoceptor agonists and of CGP 12,177 in rat and human fat cells: preliminary pharmacological evidence for a putative $\beta_{4}$-adrenoceptor. Br. J. Pharmacol. 122, 1244-1250 (1997)

10. Gasic S, Green A: Gi down-regulation and heterologous desensitization in adipocytes after treatment with the $\alpha_{2}$-agonist UK 14304. Biochem. Pharmacol. 49, 785-790 (1995)

11. Germack R, Starzec AB, Vassy R, Perret GY: $\beta$-Adrenoceptor subtype expression and function in rat white adipocytes. Br. J. Pharmacol. 120, 201-210 (1997)

12. Giorgetti S, Ballotti R, Kowalski-Chauvel A, Cormont M, Van Obberghen E: Insulin stimulates phosphatidylinositol-3-kinase activity in rat adipocytes. Eur. J. Biochem. 207, 599-606 (1992) 
13. Grillo S, Grémeaux T, Le Marchand-Brustel Y, Tanti J-F: Potential role of 3-phosphoinositide-dependent protein kinase 1 (PDK1) in insulin-stimulated glucose transporter 4 translocation in adipocytes. FEBS Lett. 461, 277-279 (1999)

14. Hazeki O, Okada T, Kurosu H, Takasuga S, Suzuki T, Katada T: Activation of PI 3-kinase by G protein $\beta \gamma$ subunits. Life Sciences 62, 1555-1559 (1998)

15. JALAS [Japanese Association for Laboratory Animal Science]: Guidelines on Animal Experimentation [in Japanese]. Exp. Anim. 36, 285-288 (1987)

16. Kelada AS, Macaulay SL, Proietto J: Cyclic AMP acutely stimulates translocation of the major insulinregulatable glucose transporter GLUT4. J. Biol. Chem. 267, 7021-7025 (1992)

17. Kelly KL, Ruderman NB, Chen KS: Phosphatidylinositol-3-kinase in isolated rat adipocytes. J. Biol. Chem. 267, 3423-3428 (1992)

18. Kelly KL, Ruderman NB: Insulin-stimulated phosphatidylinositol 3-kinase. J. Biol. Chem. 268, 4391-4398 (1993)

19. Koh H-J, Hirshman MF, He H, Li Y, Manabe Y, Balschi JA, Goodyear LJ: Adrenaline is a critical mediator of acute exercise-induced AMP-activated protein kinase activation in adipocytes. Biochem. J. 403, 473-481 (2007)

20. Kozyreva TV, Tkachenko EY, Kozaruk VP, Latysheva TV, Gilinsky MA: Effects of slow and rapid cooling on catecholamine concentration in arterial plasma and the skin. Am. J. Physiol. 276, R1668-R1672 (1999)

21. Lacasa D, Agli B, Giudicelli Y: Direct assessment of $\beta$-adrenergic receptors in intact rat adipocytes by binding of $\left[{ }^{3} \mathrm{H}\right]$ CGP 12177. Eur. J. Biochem. 146, 339-346 (1985)

22. Ludvigsen C, Jarett L, McDonald JM: The characterization of catecholamine stimulation of glucose transport by rat adipocytes and isolated plasma membranes. Endocrinology 106, 786-790 (1980)

23. Moule SK, Welsh GI, Edgell NJ, Foulstone EJ, Proud CG, Denton RM: Regulation of protein kinase B and glycogen synthase kinase-3 by insulin and $\beta$-adrenergic agonists in rat epididymal fat cells. J. Biol. Chem. 272, 7713-7719 (1997)

24. Nonen S, Yamamoto I, Liu J, Maeda M, Motomura T, Igarashi T, Fujio Y, Azuma J: Adrenergic $\beta_{1}$ receptor polymorphism (Ser49Gly) is associated with obesity in type II diabetic patients. Biol. Pharm. Bull. 31, 295-298 (2008)

25. Northup JK, Smigel MD, Sternweis PC, Gilman AG: The subunits of the stimulatory regulatory component of adenylate cyclase. J. Biol. Chem. 258, 11369-11376 (1983)

26. Ohsaka Y, Murakami T, Yoshida T, Tokumitsu Y: Comparison of atypical $\beta_{3}$-adrenoceptor agonists with their respective metabolic activities in rat white adipocytes. Jpn. J. Pharmacol. 77, 41-51 (1998)

27. Ohsaka Y, Tokumitsu Y, Nomura Y: Suppression of insulin-stimulated phosphatidylinositol 3-kinase activity by the $\beta_{3}$-adrenoceptor agonist CL316243 in rat adipocytes. FEBS Lett. 402, 246-250 (1997)

28. Omatsu-Kanabe M, Kitasato H: Insulin and noradrenaline independently stimulate the translocation of glucose transporters from intracellular stores to the plasma membrane in mouse brown adipocytes. FEBS Lett. 314, 246-250 (1992)

29. Ozanne SE, Nave BT, Wang CL, Shepherd PR, Prins J, Smith GD: Poor fetal nutrition causes long-term changes in expression of insulin signaling components in adipocytes. Am. J. Physiol. 273, E46-E51 (1997)

30. Rodbell M: Metabolism of isolated fat cells. J. Biol. Chem. 239, 375-380 (1964)

31. Sajan MP, Standaert ML, Bandyopadhyay G, Quon MJ, Burke TR, Farese RV: Protein kinase C- $\zeta$ and phosphoinositide-dependent protein kinase-1 are required for insulin-induced activation of ERK in rat adipocytes. J. Biol. Chem. 274, 30495-30500 (1999)

32. Shirakura S, Furugohri T, Tokumitsu Y: Activation of glucose transport by activatory receptor agonists of adenylate cyclase in rat adipocytes. Comp. Biochem. Physiol. 97A, 81-86 (1990)

33. Shirakura S, Tokumitsu Y: Insulin-stimulated glucose transport regulated by adenylate cyclase system in rat adipocytes. Comp. Biochem. Physiol. 96A, 503-509 (1990)

34. Simard P-M, Atgié C, Mauriège P, D’Allaire F, Bukowiecki LJ: Comparison of the lipolytic effects of norepinephrine and BRL 37344 in rat brown and white adipocytes. Obesity Res. 2, 424-431 (1994)

35. Soeder KJ, Snedden SK, Cao W, Della Rocca GJ, Daniel KW, Luttrell LM, Collins S: The $\beta_{3}$-adrenergic receptor activates mitogen-activated protein kinase in adipocytes through a $\mathrm{G}_{\mathrm{i}}$-dependent mechanism. J. Biol. Chem. 274, 12017-12022 (1999)

36. Standaert M, Bandyopadhyay G, Galloway L, Ono Y, Mukai H, Farese R: Comparative effects of GTP $\gamma$ S and insulin on the activation of Rho, phosphatidylinositol 3-kinase, and protein kinase N in rat adipocytes. J. Biol. Chem. 273, 7470-7477 (1998) 
37. Suzuki Y, Shibata H, Inoue S, Kojima I: Stimulation of glucose transport by guanine nucleotides in permeabilized rat adipocytes. Biochem. Biophys. Res. Commun. 189, 572-580 (1992)

38. Tanti J-F, Grémeaux T, Grillo S, Calleja V, Klippel A, Williams LT, Van Obberghen E, Le Marchand-Brustel Y: Overexpression of a constitutively active form of phosphatidylinositol 3-kinase is sufficient to promote Glut 4 translocation in adipocytes. J. Biol. Chem. 271, 25227-25232 (1996)

39. Tanti J-F, Grillo S, Grémeaux T, Coffer PJ, Van Obberghen E, Le Marchand-Brustel Y: Potential role of protein kinase B in glucose transporter 4 translocation in adipocytes. Endocrinology 138, 2005-2010 (1997)

40. Wesslau C, Smith U: The inhibitory GTP-binding protein (Gi) regulates the agonistic property of $\beta$-adrenergic ligands in isolated rat adipocytes. Biochem. J. 288, 41-46 (1992)

41. Zmuda-Trzebiatowska E, Manganiello V, Degerman E: Novel mechanisms of the regulation of protein kinase B in adipocytes; implications for protein kinase A, Epac, phosphodiesterases 3 and 4. Cell. Signal. 19, 81-86 (2007) 